Modern Physics Letters A, Vol. 11, Nos. 39 \& 40 (1996) 3129

(C) World Scientific Publishing Company

\title{
ERRATUM
}

\section{DUALITY AND SELF-DUAL TRIPLET SOLUTIONS IN EUCLIDEAN GRAVITY}

\author{
[Mod. Phys. Lett. A, Vol. 11, No. 34 (1996) 2669-2679]
}

S. Mahapatra

On p. 2679 , the second sentence in the acknowledgments should read "She would also like to thank ..."

The publisher is sorry for the mistake. 